\title{
Riluzole Impairs Cocaine Reinstatement and Restores Adaptations in Intrinsic Excitability and GLT-I Expression
}

\author{
Marian T Sepulveda-Orengo', Kati L Healey', Ronald Kim', Alyson C Auriemma', Jennifer Rojas', \\ Nicholas Woronoff', Rachel Hyppolite' and Kathryn J Reissner ${ }^{*, 1,2}$ \\ 'Department of Psychology and Neuroscience, University of North Carolina, Chapel Hill, NC, USA; ${ }^{2}$ Neuroscience Center, University of North \\ Carolina, Chapel Hill, NC, USA
}

\begin{abstract}
Adaptations in glutamate signaling within the brain's reward circuitry are observed following withdrawal from several abused drugs, including cocaine. These include changes in intrinsic cellular excitability, glutamate release, and glutamate uptake. Pharmacological or optogenetic reversal of these adaptations have been shown to reduce measures of cocaine craving and seeking, raising the hypothesis that regulation of glutamatergic signaling represents a viable target for the treatment of substance use disorders. Here, we tested the hypothesis that administration of the compound riluzole, which regulates glutamate dynamics in several ways, would reduce cocaine seeking in the rat self-administration and reinstatement model of addiction. Riluzole dose-dependently inhibited cue- and cocaine-primed reinstatement to cocaine, but did not affect locomotor activity or reinstatement to sucrose seeking. Moreover, riluzole reversed bidirectional cocaineinduced adaptations in intrinsic excitability of prelimbic (PL) and infralimbic (IL) pyramidal neurons; a cocaine-induced increase in PL excitability was decreased by riluzole, and a cocaine-induced decrease in IL excitability was increased to normal levels. Riluzole also reversed the cocaine-induced suppression of the high-affinity glutamate transporter I (EAAT2/GLT-I) in the nucleus accumbens (NAc). GLT-I is responsible for the majority of glutamate uptake in the brain, and has been previously reported to be downregulated by cocaine. These results demonstrate that riluzole impairs cocaine reinstatement while rectifying several cellular adaptations in glutamatergic signaling within the brain's reward circuitry, and support the hypothesis that regulators of glutamate homeostasis represent viable candidates for pharmacotherapeutic treatment of psychostimulant relapse.

Neuropsychopharmacology (2018) 43, 1212-1223; doi:10.1038/npp.2017.244; published online 8 November 2017
\end{abstract}

\section{INTRODUCTION}

Identification and reversal of cocaine-induced cellular adaptations that drive drug seeking represent a strategic approach toward development of pharmacotherapeutic treatments for cocaine relapse. Considerable evidence indicates that withdrawal from chronic cocaine leads to numerous adaptations in signaling at glutamatergic excitatory projections onto medium spiny neurons (MSNs) in the nucleus accumbens (NAc), including changes in intrinsic excitability, synaptic strength and plasticity, and glutamate uptake (Kalivas and Volkow, 2011; Kourrich et al, 2015; Uys and Reissner, 2011). Reversal of these adaptations has revealed therapeutic potential for inhibition of cocaine relapse at glutamatergic synapses, particularly those originating from the prefrontal cortex (Javitt et al, 2011; McCullumsmith and Sanacora, 2015; Roberts-Wolfe and Kalivas, 2015).

Riluzole (Rilutek, Sanofi-Aventis) is an inhibitor of voltage-gated $\mathrm{Na}+$ channels, and is FDA approved for

\footnotetext{
*Correspondence: Dr KJ Reissner, Department of Psychology and Neuroscience, UNC-CH, CB 3270, Chapel Hill, NC 27599, USA, Tel: 919843 9| 12, Fax: 919962 2537,E-mail: reissner@unc.edu Received 17 May 2017; revised 29 September 2017; accepted I October 2017; accepted article preview online 9 October 2017
}

treatment of amyotrophic lateral sclerosis (Meininger et al, 2000; Traynor et al, 2006). The multiple cellular targets of riluzole render it an intriguing candidate for inhibition of relapse to cocaine. Firstly, riluzole has been ascribed neuroprotective and anticonvulsive properties because of reduced glutamate release subsequent to $\mathrm{Na}+$ channel inhibition (for review see Machado-Vieira et al, 2009; Pittenger et al, 2008). Riluzole can also influence intrinsic excitability through modulation of potassium channels (Ahn et al, 2006; Duprat et al, 2000; Pittenger et al, 2008; Xu et al, 2001). Of relevance, an increase in cellular excitability in the dorsomedial prefrontal cortex (dmPFC) has previously been reported following withdrawal from noncontingent cocaine administration (Dong et al, 2005; Hearing et al, 2013; Nasif et al, 2005a, b, but see also Otis and Mueller, 2017).

Secondly, in addition to these effects on cellular excitability, numerous studies have reported that riluzole administration also leads to upregulation of expression and activity of glutamate transporters, in particular GLT-1, both in vitro and in vivo (Banasr et al, 2010; Brothers et al, 2013; Carbone et al, 2012; Frizzo et al, 2004; Fumagalli et al, 2008; Gourley et al, 2012; Liu et al, 2011). Cocaine withdrawal-dependent decreases in expression and activity of glutamate transporter GLT-1 in the NAc have been described (Fischer et al, 2013; Knackstedt et al, 2010), and pharmacological restoration of 
GLT-1 leads to decreased cue-primed as well as cocaineprimed reinstatement in the rat self-administration model of cocaine addiction (Knackstedt et al, 2010; Reissner et al, 2014, 2015; Sari et al, 2009). GLT-1 is responsible for $\sim 90 \%$ of glutamate uptake in the brain, and is important for protection against excitotoxicity as well as for shaping glutamatergic transmission (Danbolt, 2001; Murphy-Royal et al, 2017; Robinson and Jackson, 2016; Tzingounis and Wadiche, 2007). Given the important role for GLT-1 in glutamatergic signaling, and the suppressive effect of cocaine on GLT-1 expression and activity, current theory posits that modulation of NAc GLT-1 function can influence glutamatergic drive in the NAc that serves as a limbic motor integrator within the brain's reward circuitry (Roberts-Wolfe and Kalivas, 2015; Spencer and Kalivas, 2017). Accordingly, normalization of function would normalize transmission and the drive toward drug seeking as behavioral output.

Thirdly, riluzole has also been reported to inhibit glutamate release from presynaptic neurons because of $\mathrm{Ca}^{2+}$ channel inhibition (Cheah et al, 2010; Lamanauskas and Nistri, 2008; Siniscalchi et al, 1997); cocaine-primed reinstatement leads to potentiated release of glutamate within the NAc (McFarland et al, 2003). Thus, riluzole is pharmacologically well positioned to reverse several of the cocaine-induced changes in glutamatergic signaling that are postulated to influence drug seeking, including intrinsic excitability, glutamate release, and glutamate uptake. In order to more fully explore this potential, we sought to investigate the effects of riluzole on cue- and cocaine-primed reinstatement in the rat self-administration model of cocaine abuse. In addition, because of the fundamental role for corticostriatal glutamatergic transmission in cocaine seeking, we subsequently assessed the effects of riluzole on cocaineinduced adaptations in intrinsic excitability in the $\mathrm{MPFC}$ and on GLT-1 levels in the NAc.

\section{MATERIALS AND METHODS}

\section{Animal Care and Surgical Procedures}

Male Sprague-Dawley rats (Harlan, Boston, MA; 280 g at the time of surgery) were kept on a $12 \mathrm{~h}$ reverse light cycle. Before surgery, rats were anesthetized with ketamine hydrochloride $(100 \mathrm{mg} / \mathrm{kg})$ and xylazine $(7 \mathrm{mg} / \mathrm{kg})$ together with ketorolac analgesic $(0.28-0.32 \mathrm{mg} / \mathrm{kg})$. Chronic indwelling catheters were implanted into the right jugular vein for the administration of intravenous (i.v.) cocaine, as described previously (Scofield et al, 2016). Rats were given 5-7 days of recovery before behavioral training. Catheters were flushed daily with a prophylactic antibiotic (timentin $10.0 \mathrm{mg} / 0.1 \mathrm{ml}$, i.v., GlaxoSmithKline, Research Triangle Park, NC or gentamicin $0.5 \mathrm{mg} / 0.1 \mathrm{ml}$, i.v., Hospira, Lake Forest, IL) followed by heparinized saline $(100 \mathrm{mg} / \mathrm{ml}, 0.1 \mathrm{ml}$ i.v., Fresenius Kabi USA). Catheter testing for patency was performed periodically with propofol ( $1 \mathrm{mg} / 0.1 \mathrm{ml}$, i.v.). All experiments were approved by the institutional animal care and use committee of University of North Carolina at Chapel Hill.

\section{Behavioral Training}

All operant training was performed in a standard rat operant chamber (Med Associates, St Albans, VT). Before self-administration training, rats received a food training session (at least $6 \mathrm{~h}$ ) in which an active lever press resulted in the administration of a single food pellet $(45 \mathrm{mg} /$ pellet, BioServ) until a criterion of 100 pellets received was met. Rats subsequently received 6 food pellets of standard rat chow per day (Envigo Teklad laboratory animal diet). Selfadministration of cocaine (or saline) was performed in $2 \mathrm{~h}$ sessions on a fixed-ratio 1 (FR1) schedule of reinforcement. Each reinforced active lever press resulted in a drug infusion $(5 \mathrm{mg} / \mathrm{ml}$ cocaine hydrochloride; $0.2 \mathrm{mg}$ per infusion, i.v.; NIDA), a $5 \mathrm{~s}$ compound stimulus (cue light and tone, $70 \mathrm{~dB}$, $2.5 \mathrm{kHz}$ ), and a $20 \mathrm{~s}$ time-out period. Criteria for selfadministration were 10 days of at least 10 infusions per session. Rats were divided into treatment groups based on active lever presses during the last 3 days of selfadministration. After self-administration of cocaine (or saline), rats entered the extinction phase (16 days: $2 \mathrm{~h}$ /day in the same operant boxes as self-administration) where an active lever no longer elicited the tone, cue light, and the infusion of cocaine. Following extinction, rats received a $2 \mathrm{~h}$ cue-primed (light and tone) reinstatement test, followed by 3 days of extinction and a $2 \mathrm{~h}$ cocaine-primed reinstatement test $(10 \mathrm{mg} / \mathrm{kg}$, i.p.). Throughout extinction training and reinstatement testing, rats received either vehicle or riluzole (1 or $4 \mathrm{mg} / \mathrm{kg}$, i.p.; Toronto Research Chemicals) $30 \mathrm{~min}$ before each session. Riluzole was similarly given $30 \mathrm{~min}$ before all analyses (locomotor testing, sucrose reinstatement, electrophysiology, tissue preparation). Riluzole was prepared daily, in saline containing 2\% Tween-80 (Sigma item P6474) and mixed at room temperature for at least $1 \mathrm{~h}$ before use. Saline containing 2\% Tween-80 used to prepare riluzole was used as vehicle. In a separate set of experiments, rats were trained to self-administer sucrose (FR5; $45 \mathrm{mg} /$ pellet, TestDiet, Richmond, IL) in the same operant chambers used for cocaine studies. Sucrose-administering rats were trained in these operant chambers for the same number of days of selfadministration and extinction as cocaine-administering rats. Cue-primed sucrose reinstatement $(2 \mathrm{~h})$ was performed under an FR1 schedule for presentation of cues. Rats did not receive surgery but were administered riluzole $(4 \mathrm{mg} / \mathrm{kg})$ or vehicle in an identical manner as for cocaine experiments.

\section{Locomotor Activity}

Rats were trained in self-administration and extinction as described, receiving riluzole $(4 \mathrm{mg} / \mathrm{kg})$ or vehicle $30 \mathrm{~min}$ before each extinction session and before locomotor testing. No reinstatement test was performed on rats used for locomotor testing. On test day rats were placed in open field chamber within a sound-attenuating chamber (Med Associates). Distance traveled $(\mathrm{cm})$ was measured using activity motoring software (Med Associates) over a $2 \mathrm{~h}$ period.

\section{Whole-Cell Patch-Clamp Electrophysiology}

Measurements of neuronal excitability were taken $24 \mathrm{~h}$ after the last day of extinction. At 30 min after injection of riluzole $(4 \mathrm{mg} / \mathrm{kg})$ or vehicle, rats were deeply anesthetized with pentobarbital $(65 \mathrm{mg} / \mathrm{kg})$ and perfused transcardially with oxygenated cold modified artificial cerebral spinal fluid (aCSF)-NMDG-HEPES recovery solution and decapitated. Coronal slices $(235 \mu \mathrm{m})$ of the medial prefrontal cortex 
(mPFC) were taken using a vibratome (Leica VT1200S) in ice-cold cutting solution (in $\mathrm{mM}$ ): $125 \mathrm{NaCl}, 2.5 \mathrm{KCl}, 25$ $\mathrm{NaHCO}_{3}, 1 \mathrm{NaH}_{2} \mathrm{PO}_{4}, 25$ glucose, $6 \mathrm{MgCl}_{2}, 1.5 \mathrm{CaCl}_{2}$, and 1 kynurenic acid. Slices were incubated at $32{ }^{\circ} \mathrm{C}$ for at least $10 \mathrm{~min}$ in oxygenated NMDG-HEPES recovery solution and then $1 \mathrm{~h}$ in oxygenated HEPES holding aCSF solution at room temperature (Ting et al, 2014). Slices were transferred to the recording chamber equipped with an upright microscope with differential interference contrast (DIC) water immersion optics and perfused at $2-3 \mathrm{ml} / \mathrm{min}$ with $32{ }^{\circ} \mathrm{C}$ aCSF. Whole-cell current-clamp recordings were performed in pyramidal neurons from layer $\mathrm{V}$ located in the prelimbic cortex (PL) and infralimbic cortex (IL) at a holding potential of $-70 \mathrm{mV}$. Action potentials were evoked by injecting $800 \mathrm{~ms}$ depolarizing current pulses with the range of $20-320 \mathrm{pA}$ at $10 \mathrm{pA}$ increments with an intertrial interval of $5 \mathrm{~s}$, as described previously (Santini et al, 2008; Sepulveda-Orengo et al, 2013). Recordings were filtered at $4 \mathrm{kHz}$ (MultiClamp700B; Molecular Devices), digitized at $10 \mathrm{kHz}$, and saved to a computer using pClamp10 (Molecular Devices). Membrane potentials $\left(V_{\mathrm{m}}\right)$ were not corrected for the junction potential. The input resistance $\left(R_{\text {in }}\right)$ was measured from a $5 \mathrm{mV}, 50 \mathrm{~ms}$ depolarizing pulse in voltage-clamp mode at a holding potential of $-60 \mathrm{mV}$. The fast afterhyperpolarizing potential (fAHP) was obtained from traces showing at least three spikes. The fAHP was measured between the second and third evoked spikes by subtracting the voltage at the peak of the fAHP from the threshold potential for spike initiation (Figures $2 \mathrm{f}$ and $3 \mathrm{e}$, insert). Cells with less than three spikes were not used for the fAHP calculation. The medium afterhyperpolarizing potentials (mAHPs) and slow afterhyperpolarizing potentials

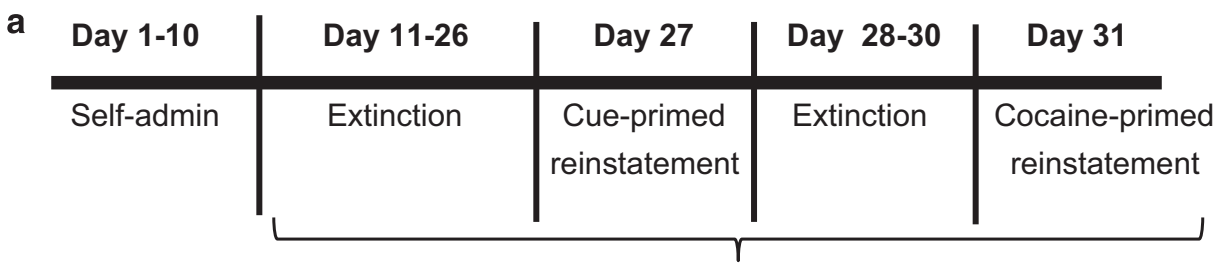

Riluzole or vehicle i.p. administration

b

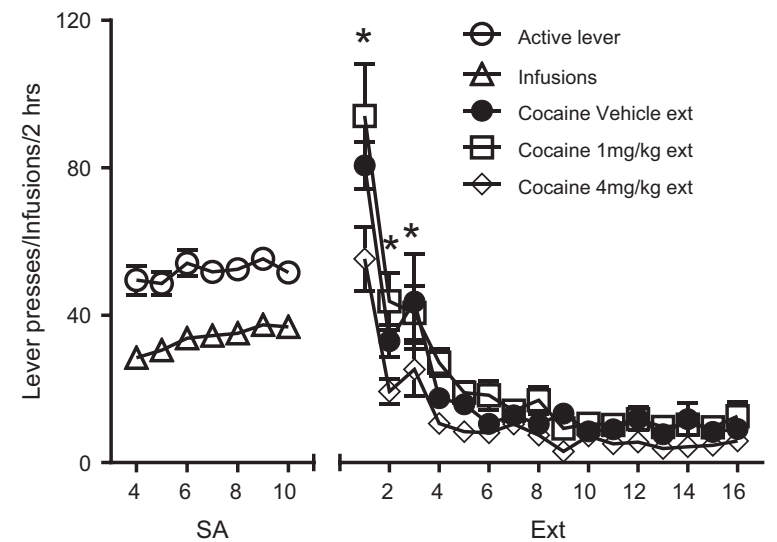

c

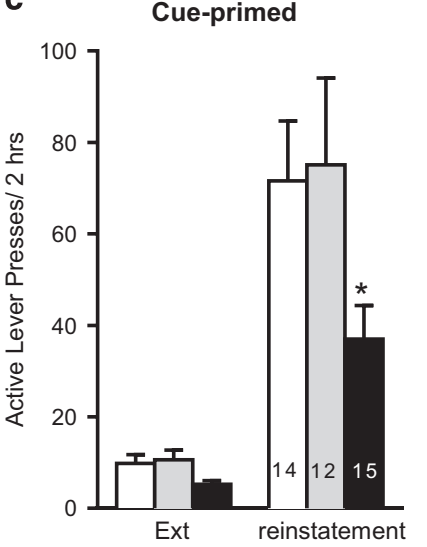

d

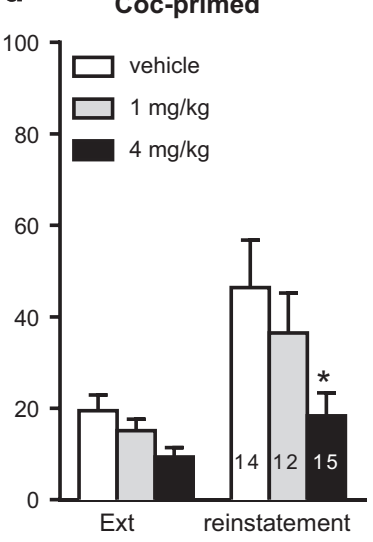

e

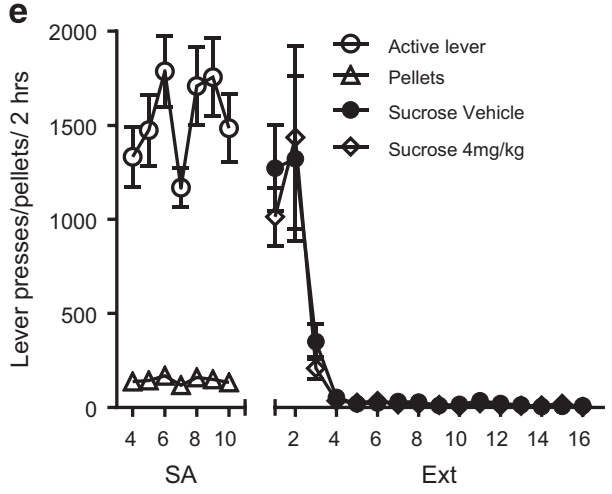

f

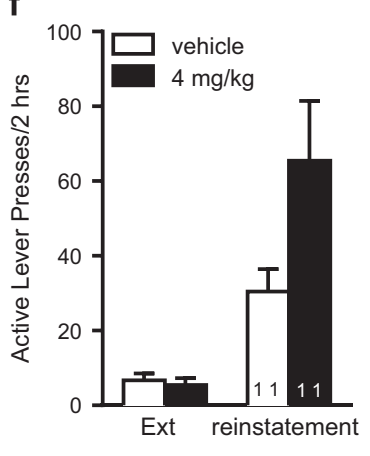

g

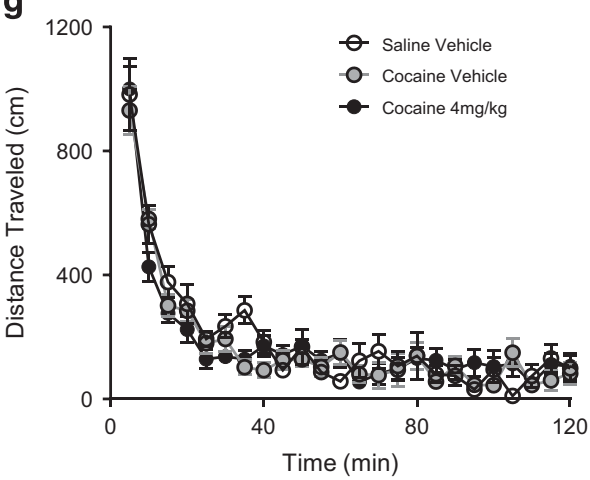

Figure I Riluzole inhibits cocaine reinstatement without impairment on locomotor activity or sucrose reinstatement. (a) Schematic of self-administration $(\mathrm{SA})$, extinction (Ext), and reinstatement testing. At 30 min before each extinction or reinstatement session, rats were injected intraperitoneally (i.p.) with $4 \mathrm{mg} / \mathrm{kg}$ riluzole, I mg/kg riluzole, or vehicle. (b) Active lever presses and infusions for all rats across groups during the last 7 days of cocaine SA and throughout extinction training. Extinction pressing is shown separately for respective treatment groups. * 1 ndicates $4 \mathrm{mg} / \mathrm{kg}$ riluzole-treated significantly different from vehicle-treated. (c, d) Active lever presses for each group during the last day of extinction, and during cue- and cocaine-primed reinstatement tests. (e) Active lever pressing and number of sucrose pellets during sucrose SA and Ext. (f) Active lever presses during the last day of Ext and during the cue-primed sucrose reinstatement test. (g) Open field locomotor activity of Saline-Vehicle, Cocaine-Vehicle, and Cocaine-4 mg/kg rats. 
(sAHPs) were measured after the end of the $800 \mathrm{~ms}$ pulse. The mAHP was measured as the peak of the AHP, and the sAHP was measured as the average potential during a $50 \mathrm{~ms}$ period beginning $280 \mathrm{~ms}$ after the end of the $800 \mathrm{~ms}$ depolarizing pulse (Faber and Sah, 2002; Santini et al, 2008; Sepulveda-Orengo et al, 2013). For these experiments, the internal solution contained the following (in $\mathrm{mM}$ ): 140 K-Glu, 10 HEPES, $12 \mathrm{KCl}, 0.2$ EGTA, 10 HEPES, 5 biocytin, $0.3 \mathrm{GTP}$, and 4 ATP. $\mathrm{pH}$ was adjusted to 7.4 with $\mathrm{KOH}$ (300 mOsm). For morphological identification and localization of IL and PL neurons, $5 \mathrm{mM}$ biocytin was included in the recording solution and slices were fixed overnight at $4{ }^{\circ} \mathrm{C}$ in $4 \%$ paraformaldehyde. Standard avidin-biotin peroxidase (Vectastain ABC kit; Vector Laboratories, Burlingame, CA) procedure was performed to visualize the neurons with bright-field microscopy as described previously (Porter et al, 2001). Neurons that did not have pyramidal shape were excluded from the analysis.

\section{Western Blot}

At $24 \mathrm{~h}$ after the last extinction session, rats were treated with a final administration of vehicle or riluzole $(4 \mathrm{mg} / \mathrm{kg})$ and rapidly decapitated $30 \mathrm{~min}$ later for preparation of nucleus accumbens tissue. Tissue predominantly containing core, but probably also some shell, was homogenized by hand, and a P2 crude membrane preparation was prepared as previously described (Knackstedt et al, 2010; Reissner et al, 2014). A subset of rats used for western analysis was subjected to locomotor testing immediately before rapid decapitation (Figure 1g). P2 membrane pellets were stored at $-80^{\circ} \mathrm{C}$ until use. Pellets were suspended in $35 \mu \mathrm{l}$ of $1 \times$ RIPA buffer supplemented with 1.0\% SDS and 1:100 Halt protease inhibitors containing EDTA (Thermo Scientific). Samples were centrifuged for $10 \mathrm{~min}$ at $14000 \mathrm{~g}$ and supernatant was taken for protein determination by the BCA method (Thermo Scientific). Samples were heated at $50{ }^{\circ} \mathrm{C}$ for $30 \mathrm{~min}$, and equal $\mu \mathrm{g}$ of protein was separated per lane on $10 \%$ Criterion Tris- $\mathrm{HCl}$ gels (Bio-Rad) and transferred $1.5 \mathrm{~h}$ at $150 \mathrm{~mA}$ onto PVDF membranes. Membranes were blocked for $1 \mathrm{~h}$ at room temperature in Licor Odyssey Tris blocking solution and incubated with primary antibodies overnight at $4{ }^{\circ} \mathrm{C}$ (Millipore AB1783, 1:2000; Enzo ADISPA-860-D, 1:4000). Secondary antibody incubation was performed for $1.5 \mathrm{~h}$ at room temperature (800CW antiguinea pig and 680RP anti-rabbit, Licor, 1:15000 each). Westerns were imaged and quantified on a Licor Odyssey Fc imager. GLT-1/calnexin ratio was measured and normalized to samples from saline-administering rats.

\section{Statistical Analysis}

Behavioral and electrophysiology data were analyzed using a two-way repeated measures analysis of variance (ANOVA). Western blots for GLT-1 were analyzed with a two-way ANOVA. A three-factor, mixed model, repeated measures ANOVA was used for analysis of action potentials elicited across increasing current intensities in pyramidal neurons from saline- and cocaine-extinguished rats treated with vehicle or riluzole. Significant main effects were followed by Fisher's (PLSD) post hoc tests. The electrophysiological data such as interspike interval (ISI), number of spikes evoked, and AHPs were analyzed using Clampfit 10 (Axon Instruments, Union City, CA). Two-way, repeated measures ANOVA was used for planned comparisons between specific properties of PL and IL neurons (Table 1). Values are reported as mean $\pm S E M$, and significance was considered as $p \leqslant 0.05\left({ }^{*} p<0.05\right)$.

\section{RESULTS}

\section{Riluzole Administration Impairs Cocaine Reinstatement}

The timeline for behavioral training and riluzole or vehicle administration is shown in Figure 1a. No differences were observed between treatment groups in active lever presses or infusions during self-administration $\quad\left(\mathrm{F}_{(2,38)}=0.7125\right.$, $p>0.05 ; F_{(2,38)}=0.1213, p>0.05$, respectively); Figure $1 b$

Table I Electrophysiological Properties of PL and IL Neurons

\begin{tabular}{|c|c|c|c|c|c|c|}
\hline \multicolumn{7}{|l|}{$P L$} \\
\hline Saline-4 mg/kg & $-71.8 \pm 1.3$ & $90.1 \pm 6.7$ & $90.1 \pm 7.8$ & $30.9 \pm 1.2$ & $-0.8 \pm 0.3$ & $-1.6 \pm 0.5$ \\
\hline Cocaine-Vehicle & $-69.9 \pm 1.3$ & $87.2 \pm 7.7$ & $101.8 \pm 10.1$ & $29.8 \pm 1.1$ & $-0.6 \pm 0.2$ & $-1.1 \pm 0.2$ \\
\hline Cocaine-4 mg & $-65.7 \pm 1.3$ & $81.8 \pm 5.0$ & $110.8 \pm 10.0$ & $31.5 \pm 1.3$ & $-0.8 \pm 0.2$ & $-1.1 \pm 0.2$ \\
\hline \multicolumn{7}{|l|}{ IL } \\
\hline Saline-Vehicle & $-65.8 \pm 1.3$ & $93.9 \pm 5.6$ & $81.9 \pm 5.2 *$ & $31.9 \pm 0.8$ & $-1.8 \pm 0.3$ & $-2.2 \pm 0.3$ \\
\hline Saline-4 mg/kg & $-68.1 \pm 1.8$ & $115.0 \pm 10.0$ & $72.0 \pm 9.5$ & $30.4 \pm 1.3$ & $-1.0 \pm 0.4$ & $-1.6 \pm 0.4$ \\
\hline Cocaine-Vehicle & $-66.6 \pm 1.0$ & $108.9 \pm 13.3$ & $94.8 \pm 9.8$ & $30.7 \pm 0.9$ & $-1.46 \pm 0.3$ & $-2.2 \pm 0.4$ \\
\hline Cocaine-4 mg & $-68.5 \pm 1.5$ & $90.8 \pm 6.8$ & $78.0 \pm 6.7 *$ & $28.5 \pm 1.0$ & $-1.4 \pm 0.2$ & $-2.3 \pm 0.3$ \\
\hline
\end{tabular}

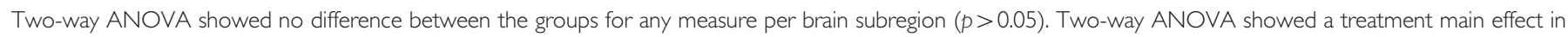
the amount of depolarizing current necessary to evoke an action potential (rheobase) between subregions $\left(F_{(3,190)}=5.128, p<0.05\right)$. Tukey's post hoc multiple

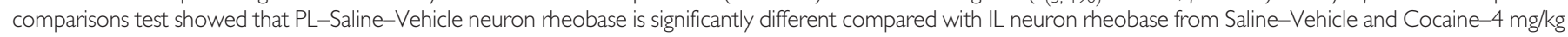
groups (* $p<0.05)$. 
a

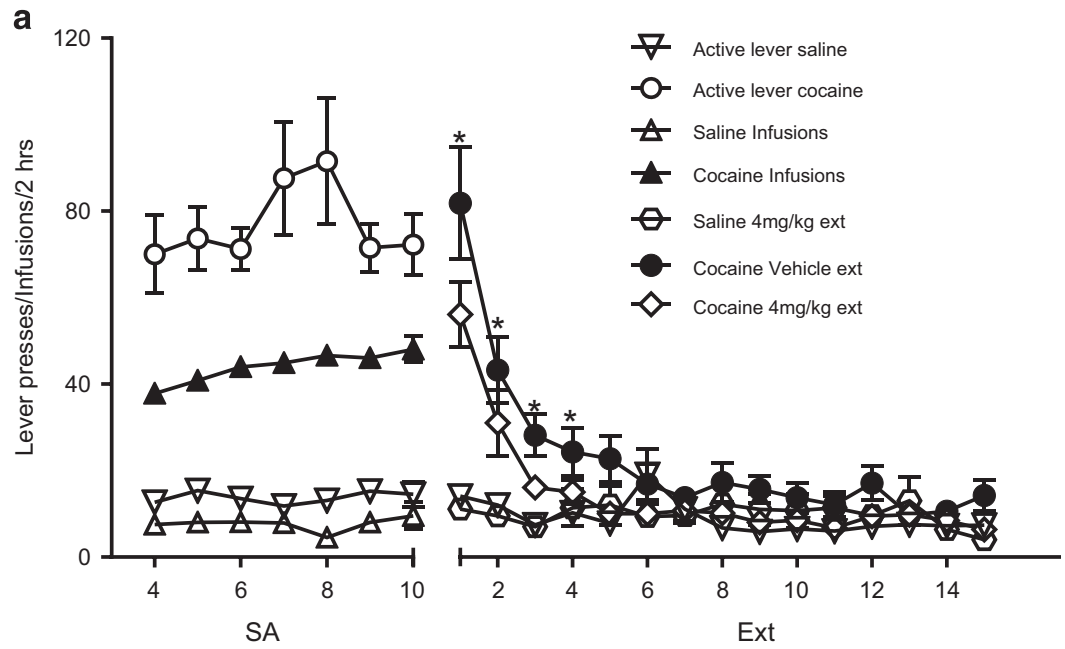

b

Saline Vehicle

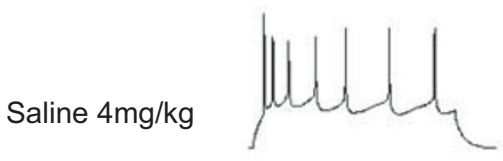

Cocaine Vehicle Cocaine $4 \mathrm{mg} / \mathrm{kg}) \mathrm{L}_{2}$

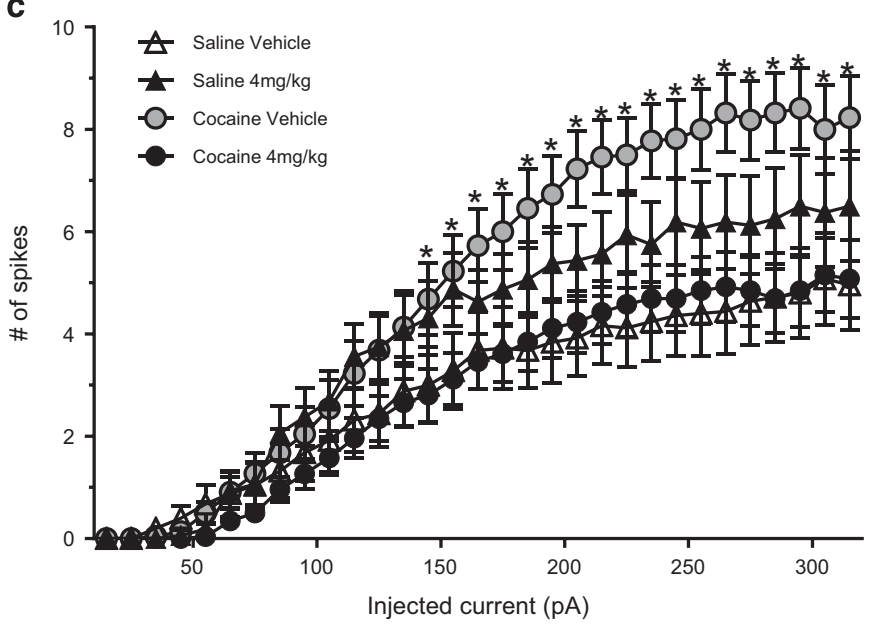

f _.... Saline Vehicle _... Saline $4 \mathrm{mg} / \mathrm{kg}$
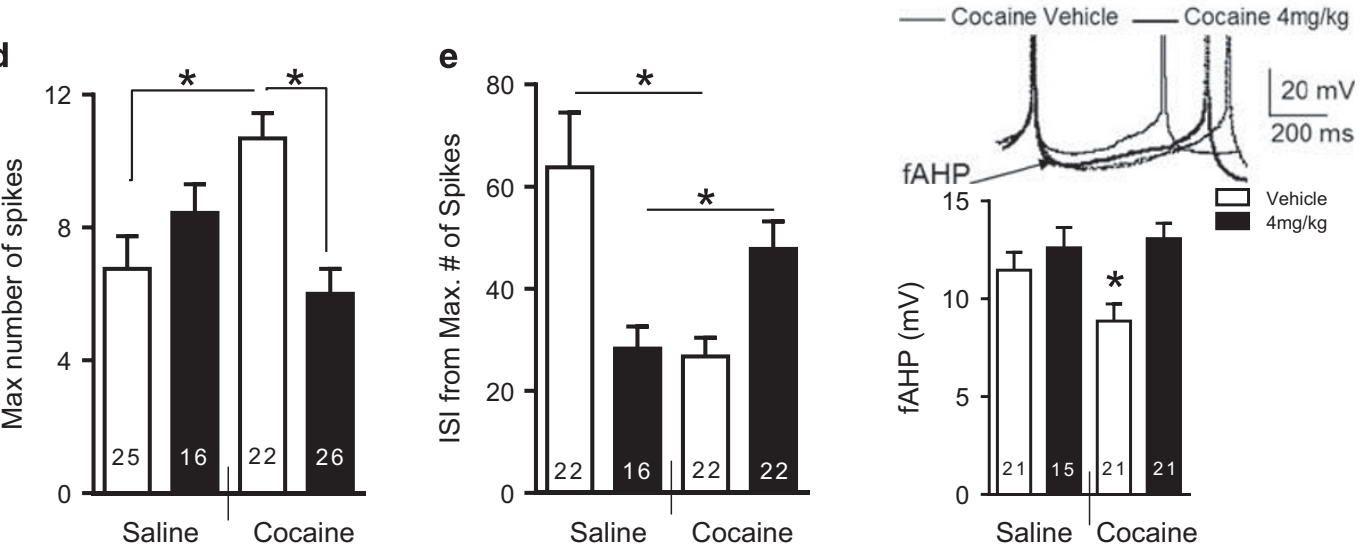

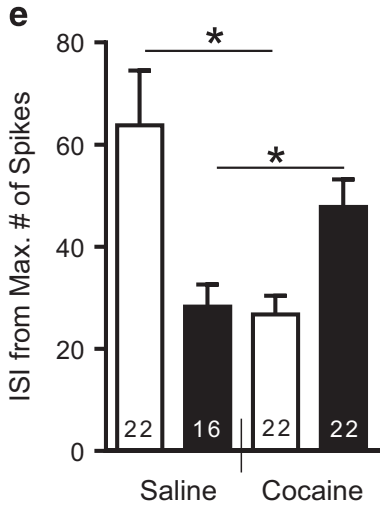

Figure 2 Riluzole prevents cocaine-induced intrinsic changes in PL pyramidal neuron. (a) Active lever presses and infusions during cocaine or saline SA for all rats from which neurons were recorded in PL and IL. Before each extinction (Ext) session, rats were injected i.p. with $4 \mathrm{mg} / \mathrm{kg}$ riluzole (Cocaine $4 \mathrm{mg} / \mathrm{kg}$, $N=$ |4; Saline-4 mg/kg, $N=8$ ) or vehicle (Cocaine-Vehicle, $N=12$; Saline-Vehicle, $N=13$ ). *Indicates significant difference between Cocaine-Vehicle and Cocaine $-4 \mathrm{mg} / \mathrm{kg}$ groups. (b) Example traces from each group. (c) Number of spikes evoked by depolarizing steps of increasing current in the four groups (Cocaine-4 mg/ $/ \mathrm{kg}, N=14, n=26$; Saline-4 mg/kg, $N=8, n=16$; Cocaine-Vehicle, $N=12, n=22$; Saline-Vehicle, $N=13, n=25$ ). (d) Bar graph shows the maximum number of evoked spikes at any current step. (e) Duration of the first ISI from maximum number of spikes. (f) Group data of the fAHP measured after the second evoked spike. For $(\mathrm{d}-\mathrm{f}), \mathrm{x}$ axis indicates the self-administration group, and legend indicates treatment with riluzole or vehicle. In ( $\mathrm{f}$, * $p<0.05$ as compared with all other groups in ( $f$ ). $N=$ number of rats; $n=$ number of cells. 
shows the combined self-administration behavior from rats in the three groups. Main effects of both time and treatment were observed across extinction (treatment: $\mathrm{F}_{(2,38)}=7.508$, $p<0.05$; time: $\left.\mathrm{F}_{(14,532)}=64.20, p<0.05\right)$, with significantly fewer active lever presses observed in $4 \mathrm{mg} / \mathrm{kg}$ riluzoletreated rats, as compared with vehicle-treated rats, on extinction days 1 through $3(p<0.05)$. Rats treated with $4 \mathrm{mg} / \mathrm{kg}$ but not $1 \mathrm{mg} / \mathrm{kg}$ riluzole during extinction demonstrated a reduction of both cue- and cocaine-primed reinstatement (Figure $1 \mathrm{c}$ and d). Two-way, repeated measures ANOVA indicated all rats reinstated cocaine seeking compared with extinction responding and that there was an effect of treatment (Cue: $\mathrm{F}_{(1,38)}=50.28, p<0.001$; $\mathrm{F}_{(2,38)}=3.125, \quad p=0.05, \quad$ Coc: $\mathrm{F}_{(1,38)}=20.51, \quad p<0.0001$; $\mathrm{F}_{(2,38)}=4.125, p<0.05$ respectively). The post hoc comparisons revealed a significant attenuation of active lever presses in the $4 \mathrm{mg} / \mathrm{kg}$ riluzole group compared with vehicle in cueas well as cocaine-primed reinstatement $(p<0.05$ and $p<0.005)$. In addition, $4 \mathrm{mg} / \mathrm{kg}$ riluzole group had significantly reduced cocaine seeking compared with the $1 \mathrm{mg} / \mathrm{kg}$ riluzole in cocaine-primed reinstatement $(p<0.05)$. No differences were observed between treatment groups in active lever presses on the last day of extinction training before cue- or cocaine-primed reinstatement $(p>0.05$ and $p>0.05)$. Thus, riluzole dose-dependently impairs cocaine reinstatement. Henceforth, the effective dose $(4 \mathrm{mg} / \mathrm{kg})$ of riluzole was used in the following experiments.

\section{Riluzole Administration Does Not Attenuate Sucrose Reinstatement or Locomotor Activity}

In order to investigate the effects of riluzole on nondrug reward, a separate cohort of rats was used to assess the effects of riluzole on reinstatement to sucrose seeking (Figure 1e and $\mathrm{f}$ ). In contrast to cocaine extinction, no differences were observed between Sucrose-Vehicle and Sucrose-4 mg/kg riluzole in active lever presses across days of extinction $\left(F_{(1,224)}=0.2138, p>0.05\right)$. In addition, in contrast to cocaine, $4 \mathrm{mg} / \mathrm{kg}$ riluzole did not suppress cue-primed reinstatement to sucrose. In fact, a nonsignificant trend toward an increase in reinstatement was observed following administration of riluzole. Two-way, repeated measures ANOVA indicated a significant main effect of reinstatement $\left(\mathrm{F}_{(1,20)}=23.88, \quad p<0.0001\right.$; Figure 1f), but no effect of riluzole $\left(\mathrm{F}_{(1,20)}=3.771, p=0.0664\right.$.

Because sedative effects of riluzole can be observed at high doses (Lourenco Da Silva et al, 2003; Sugiyama et al, 2012), and to further ensure that effects on cocaine reinstatement were not because of a sedative effect, locomotor testing was subsequently performed in an additional cohort of rats. This was particularly important, given the effect of riluzole on cocaine extinction pressing. Rats were trained on self-administration and extinction to cocaine, and were treated with vehicle or $4 \mathrm{mg} / \mathrm{kg}$ riluzole across extinction in a manner identical to those tested for reinstatement. No differences in locomotor activity or distance traveled over $2 \mathrm{~h}$ in an open field were observed $\left(\mathrm{F}_{(2,26)}=0.4277, p>0.05 ;\right.$ Figure 1g). Accordingly, the effective dose of riluzole against cocaine reinstatement had no effect on cue-primed sucrose reinstatement or locomotor activity.

\section{Riluzole Administration Prevents Cocaine-Induced Hyperexcitability in PL Neurons}

The $\mathrm{PL}$ region of the $\mathrm{mPFC}$ is necessary for cocainereinforced responses (Gipson et al, 2013; McFarland and Kalivas, 2001), and increased PL excitability has been previously reported following noncontingently administered cocaine (Dong et al, 2005; Hearing et al, 2013; Nasif et al, $2005 a, b)$. Because riluzole is known to block action potential firing, we hypothesized that riluzole would rectify cocaineinduced hyperexcitability. Rats were trained in saline or cocaine self-administration, and treated with either vehicle or $4 \mathrm{mg} / \mathrm{kg}$ riluzole, respectively, as for previous experiments. Whole-cell slice electrophysiology recordings were performed $24 \mathrm{~h}$ after the last extinction section. Self-administration and extinction behavior for rats used in electrophysiology studies is shown in Figure 2a. Similarly, as observed in behavior experiments, there was no difference between rats during cocaine self-administration $\left(\mathrm{F}_{(1,120)}=0.2677, p>0.05\right.$, comparing cocaine-administering groups only), but an effect of treatment was observed across extinction $\left(\mathrm{F}_{(3,43)}=9.11\right.$, $p<0.05)$. Significantly fewer active lever presses were observed in Cocaine $-4 \mathrm{mg} / \mathrm{kg}$ riluzole-treated rats compared with vehicle-treated cocaine-administering rats on days 1-3 and day 5 of extinction.

In agreement with previous studies, we observed a cocaine-dependent increase in intrinsic excitability of PL pyramidal neurons that was reversed by administration of riluzole (Figure $2 \mathrm{~b}$ and $\mathrm{c}$ ). A three-way mixed model ANOVA with current as the repeated measures factor and group (cocaine $v s$ saline self-administering rats) and treatment (vehicle vs $4 \mathrm{mg} / \mathrm{kg}$ riluzole) as between-subjects factors was used to examine differences in the number of spikes in the PL (Figure 2c). There was a main effect of current $\left(\mathrm{F}_{(32,2720)}=132.97, p<0.001\right)$, and the current $x$ group interaction $\left(\mathrm{F}_{(32,2720)}=1.92, p<0.05\right)$, current $x$ group $\times$ treatment interaction $\left(\mathrm{F}_{(32,2720)}=20.7, p<0.001\right)$, and group $\times$ treatment interactions were significant $\left(\mathrm{F}_{(1,85)}=8.91, p<0.05\right)$. The post hoc comparisons showed that within saline self-administering rats, there was no significant difference between vehicle and $4 \mathrm{mg} / \mathrm{kg}$ riluzoletreated rats $(p=0.17)$. Within cocaine self-administering rats, there was a significant difference between treatment groups $(p<0.05)$. Cocaine self-administering rats treated with vehicle showed a significantly greater number of spikes than riluzole-treated rats. When comparing number of spikes from vehicle-treated rats, there was a significant difference between saline and cocaine self-administering rats $(p<0.05)$, with cocaine self-administering rats showing significantly more spikes than saline self-administering rats. However, within riluzole-treated rats, there was no significant difference in spikes between saline and cocaine self-administering rats $(p=0.15)$.

In addition to the number of evoked spikes, we examined neuronal excitability parameters such as the ISI and AHPs. The AHP is divided in three types, sAHP, mAHP, and fAHP, that contribute differentially to neuronal excitability. The fAHP occurs within the first $10 \mathrm{~ms}$ following an action potential, and contributes to the repolarization of the neuron. The sAHP and mAHP are more prolonged AHPs, lasting several hundred $\mathrm{ms}$ to several seconds, and mediate firing 
Saline Vehicle

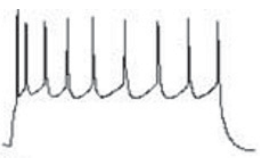

Saline $4 \mathrm{mg} / \mathrm{kg}$

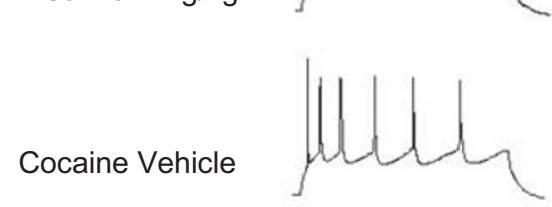

Cocaine $4 \mathrm{mg} / \mathrm{kg}$

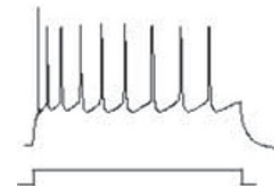

b

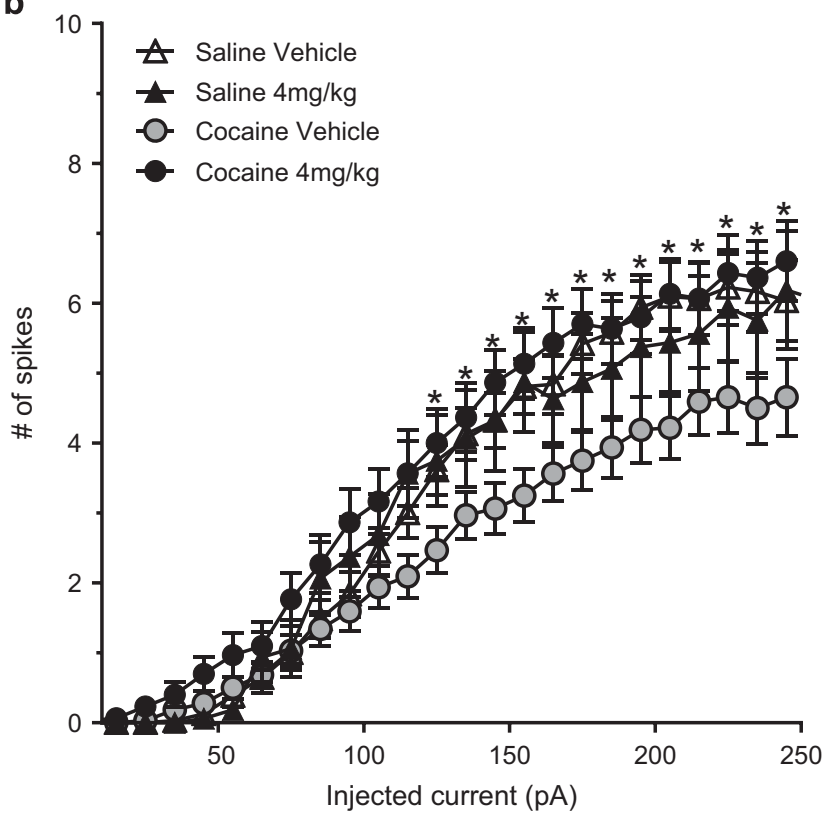

C

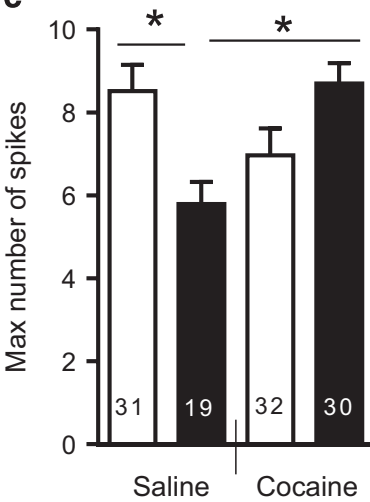

d

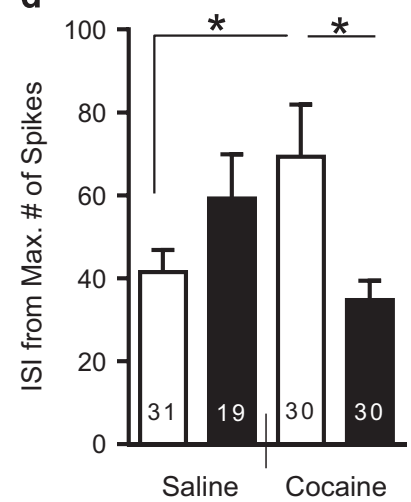

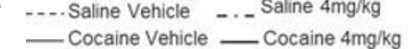
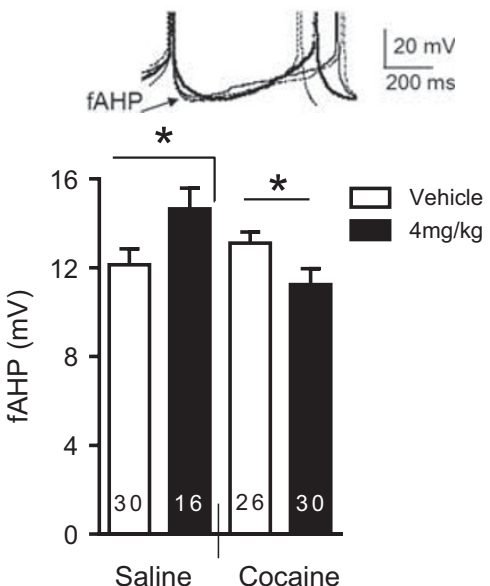

Figure 3 Riluzole reverses cocaine-induced decrease in intrinsic excitability in IL pyramidal neurons. (a) Example traces from each group. (b) Number of spikes evoked by depolarizing steps of increasing current (Cocaine $-4 \mathrm{mg} / \mathrm{kg}, N=14, n=30$; Saline $-4 \mathrm{mg} / \mathrm{kg}, N=8, n=19 ;$ Cocaine-Vehicle, $N=12, n=32$; Saline-Vehicle, $N=13, n=31$ ). (c) Maximum number of evoked spikes at any current step. (d) Group of data showing the duration of the first ISI from two spike traces. (e) Group data of the fAHP measured after the second evoked spike. $* p<0.05$ post hoc comparisons as indicated by the bar.

frequency and spike-frequency adaptations (Bean, 2007; Faber and Sah, 2003).

No differences were observed in sAHP, mAHP, input resistance $\left(R_{\text {in }}\right)$, threshold at action potential, resting membrane potential $\left(V_{\mathrm{m}}\right)$, or the amount of depolarizing current necessary to evoke an action potential (rheobase) among the groups (Table 1). As shown in Figure 2e, neurons from the Cocaine-Vehicle group exhibited a significantly smaller ISI from maximum fired spikes compared with the Saline-Vehicle group that was reverse by riluzole. Two-way ANOVA indicated an interaction $\left(\mathrm{F}_{(1,79)}=16.41, p<0.001\right)$, and post hoc comparisons showed that the ISI number from maximum evoked spikes in the Cocaine-Vehicle group was significantly smaller than in the Cocaine $-4 \mathrm{mg} / \mathrm{kg}$ and Saline-Vehicle $(p<0.05)$, but not than Saline- $4 \mathrm{mg} / \mathrm{kg}$ $(p=0.8821)$. In addition, post hoc comparisons showed that the ISI number from maximum evoked spikes in the
Saline $-4 \mathrm{mg} / \mathrm{kg}$ was significantly smaller than in the SalineVehicle $(p<0.05)$, indicating an effect of riluzole on this excitability measure in saline-experienced rats. In addition, we measured the fAHPs evoked by the second spike (Figure 2f) as previously described (Duvarci and Pare, 2007). Neurons from the Cocaine-Vehicle group had smaller fAHPs than neurons from either the Cocaine $-4 \mathrm{mg} / \mathrm{kg}$, Saline-Vehicle, or Saline- $4 \mathrm{mg} / \mathrm{kg}$ groups (main effect of group $\left(\mathrm{F}_{(1,80)}=4.14, p<0.05\right)$, post hoc comparisons between: Cocaine-Vehicle and Cocaine- $4 \mathrm{mg} / \mathrm{kg}(p<0.005)$, Cocaine-Vehicle and Saline-Vehicle $(p<0.05)$, CocaineVehicle and Saline $-4 \mathrm{mg} / \mathrm{kg}(p<0.05)$. Collectively, these results indicate that riluzole prevents the cocaine-induced increase in PL pyramidal neuron excitability that correlates with the normalization of maximum number of spikes, ISI, and fAHP. 


\section{Riluzole Administration Prevents Cocaine-Induced Hypoexcitability in IL Neurons}

Whereas the PL is generally associated with goal-directed behavior, the IL subregion of the MPFC is known to be important in cocaine extinction learning (LaLumiere et al, 2010; Moorman et al, 2014). Therefore, we also tested the effects of cocaine history and riluzole administration on neuronal excitability in the IL. Interestingly, and opposed to results obtained from the PL, excitability in the IL neurons following extinction from cocaine self-administration was significantly reduced, an effect that was reversed by systemic riluzole administration (Figures 3a-e). A three-way mixed ANOVA with current as the repeated measures factor and group (cocaine $v s$ saline self-administering rats) and treatment (vehicle vs $4 \mathrm{mg} / \mathrm{kg}$ riluzole) as between-subjects factors was used to examine differences in the number of spikes in the IL. There was a main effect of current $\left(\mathrm{F}_{(25,2700)}=228.43, p<0.001\right)$, and the current $\times$ treatment interaction $\left(\mathrm{F}_{(25,2700)}=1.70, \quad p<0.05\right)$, the current $x$ group $\times$ treatment interaction $\left(\mathrm{F}_{(25,2700)}=8.51, p<0.001\right)$, and group $\times$ treatment interaction were significant $\left(\mathrm{F}_{(1,108)}=8.32, p<0.05\right)$. The post hoc comparisons showed that within saline self-administering rats, there was no significant difference in the number of spikes in the IL between vehicle and $4 \mathrm{mg} / \mathrm{kg}$ riluzole-treated rats $(p=0.25)$. However, within cocaine self-administering rats, there was a significant difference between treatment groups $(p<0.05)$. Cocaine self-administering rats treated with riluzole showed a significantly greater number of spikes than cocaine selfadministering rats treated with vehicle. When comparing within treatment groups, post hoc comparisons show that in vehicle-treated rats, there was a significant difference between saline and cocaine self-administering rats $(p<0.05)$. Cocaine self-administering rats treated with vehicle showed significantly fewer spikes than saline selfadministering rats treated with vehicle. Within riluzoletreated rats, there was also a significant difference in spikes between saline and cocaine self-administering rats $(p=0.05)$. Cocaine self-administering rats treated with riluzole showed significantly more spikes than saline self-administering rats treated with riluzole.

The maximum number of evoked spikes in IL neurons in the Cocaine-Vehicle group was lower than Cocaine- $4 \mathrm{mg} / \mathrm{kg}$ group but not than Saline-Vehicle or Saline- $4 \mathrm{mg} / \mathrm{kg}$ (Figure 3c). Two-way ANOVA indicated an interaction between self-administration and treatment $\left(\left(\mathrm{F}_{(1,108)}=13.15\right.\right.$, $p<0.001)$, post hoc comparisons showed Cocaine-Vehicle lower than Cocaine $-4 \mathrm{mg} / \mathrm{kg}(p<0.05)$ but not lower than Saline- $4 \mathrm{mg} / \mathrm{kg}(p=0.22)$ or Saline-Vehicle $(p=0.056)$. The maximum number of spikes was significantly reduced in the Saline- $4 \mathrm{mg} / \mathrm{kg}$ group, as compared with the SalineVehicle group (Figure 3c). In addition, we measured the ISI from maximum number of evoked spikes and fAHPs (Figure $3 \mathrm{~d}$ and e). Two-way ANOVA showed a significant interaction for both measurements $\left(F_{(1,107)}=8.35, p<0.01\right.$, $\left.\mathrm{F}_{(1,99)}=10.38, p<0.01\right)$. The post hoc comparisons indicated that the Cocaine-Vehicle group had a higher ISI than the Cocaine $-4 \mathrm{mg} / \mathrm{kg} \quad(p<0.05)$ and Saline-Vehicle groups $(p<0.05)$ but not than Saline $-4 \mathrm{mg} / \mathrm{kg}(p>0.05)$, and that neurons from the Cocaine $-4 \mathrm{mg} / \mathrm{kg}$ group had smaller fAHPs than neurons from Cocaine-Vehicle $(p<0.05)$ and
Saline- $4 \mathrm{mg} / \mathrm{kg}$ groups $(p<0.05)$, but not than SalineVehicle $(p>0.05)$. There were no differences in sAHP, $\mathrm{mAHP}$, input resistance, resting membrane potential, threshold of action potential, or the amount of depolarizing current necessary to evoke an action potential (rheobase) among the groups (Table 1). These results show that riluzole prevents cocaine-induced decreased excitability in IL and normalizes maximum number of spikes, ISI, and fAHP.

Because different effects were observed in neuronal excitability from cocaine-extinguished rats in the PL and IL, we sought to determine whether preexisting differences in membrane properties might exist between neurons in these regions. No differences were observed in resting membrane potential between the PL and IL among treatment groups (Table 1); however, the amount of depolarizing current necessary to evoke an action potential (rheobase) among the groups was significantly different between PL and IL neurons from saline extinguished rats (Table 1), indicating subregion differences in neuronal properties.

\section{Riluzole Restores the Cocaine-Induced Decrease in NAc GLT-1 Expression}

We next examined the effect of riluzole on GLT-1 expression in the NAc from rats following self-administration and extinction (Figure 4). A two-way ANOVA showed significant main effects of cocaine and treatment $\left(\mathrm{F}_{(1,54)}=5.92, p<0.05\right.$, $\mathrm{F}_{(1,54)}=10.74, p<0.01$, respectively). The post hoc comparisons revealed that the Cocaine-Vehicle group had lower NAc GLT-1 expression as compared with the Saline-Vehicle $(p<0.01)$, Saline $-4 \mathrm{mg} / \mathrm{kg}(p<0.01)$, and Cocaine $-4 \mathrm{mg} / \mathrm{kg}$ groups $(\mathrm{p}<0.05)$. This result replicates previous results that indicate a cocaine-induced decrease in GLT-1 expression in the NAc, and show that this can be normalized by riluzole.
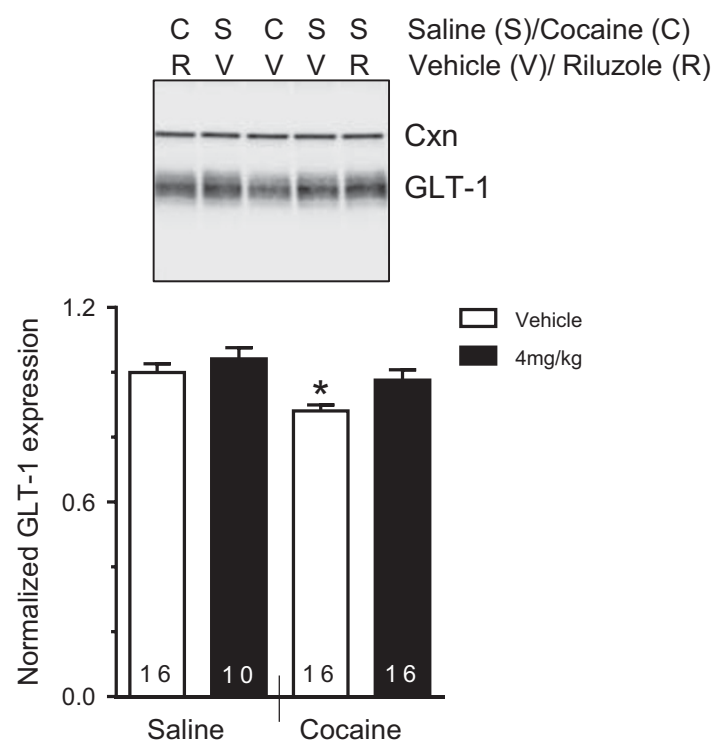

Figure 4 Riluzole blocks cocaine-induced decrease in GLT-I. Normalized GLT-I/CXn expression. Expression levels are normalized to Saline-Vehicle. Representative western blots showed bands corresponding to GLT-I and calnexin (Cxn, control loading protein) expression from Saline-Vehicle, Saline- $4 \mathrm{mg} / \mathrm{kg}$, Cocaine-Vehicle, and Cocaine $-4 \mathrm{mg} / \mathrm{kg}$ groups. $* P<0.05$ compared with all other groups. The $x$ axis indicates self-administration group, and legend indicates treatment group. 


\section{DISCUSSION}

\section{Riluzole Administration Reduces Cocaine Reinstatement, But Not Sucrose Reinstatement}

Results presented herein indicate that riluzole impairs cocaine reinstatement, normalizes cellular excitability within the $\mathrm{mPFC}$, and restores the cocaine-induced decrease in GLT-1 in the nucleus accumbens. Behaviorally, our results indicate that administration of riluzole dose-dependently impairs cocaine reinstatement, but does not affect sucrose reinstatement. In support of the behavioral effect of riluzole on cocaine seeking, it has recently been shown that microinjection of riluzole directly into the laterodorsal tegmental nucleus (LDT) blocked expression of cocaine conditioned place preference (CPP) (Kamii et al, 2015). These findings collectively suggest that an FDA-approved medication carries potential as a substance abuse therapeutic agent, and also shed light on the effects of cocaine selfadministration on cellular excitability.

\section{Riluzole Restores Cocaine-Induced Adaptations in Intrinsic Excitability in the mPFC}

Although a substantial body of literature exists on the synaptic consequences of drug self-administration (Bowers et al, 2010; Korpi et al, 2015; Luscher and Malenka, 2011; Wolf, 2016), less is known about how drugs of abuse affect intrinsic excitability (Kourrich et al, 2015), in particular in the PFC. We show that pyramidal neuron excitability is increased in the PL of cocaine-extinguished rats, but decreased in the IL. Increased PL excitability following noncontingent cocaine injections and withdrawal has previously been reported, dependent on a reduction in voltage-gated potassium channels and an increase in voltagesensitive Ca2+ channels (Dong et al, 2005; Hearing et al, 2013; Nasif et al, 2005a, b; Nasif et al, 2005b, but see also Otis and Mueller, 2017). Moreover, an increase in PL neuron excitability in cocaine-extinguished rats has been reported in abstract form (Buchta and Riegel, 2015). Our results similarly show that cocaine self-administration and extinction leads to increased intrinsic excitability in PL neurons by a reduction of the fAHP. The fAHP is predominantly (although not exclusively) governed by the conductance of voltage-gated and $\mathrm{Ca}^{2+}$-dependent potassium channels (Oh et al, 2010). Interestingly, it has been shown that decreased PL excitability accompanies resistance to punishment induced by cocaine self-administration (Chen et al, 2013). In this case, deficits in PL neuronal activity were observed after prolonged exposure to cocaine ( $>8$ weeks of extended access), in contrast to the more moderate exposure paradigms utilized here and elsewhere (Dong et al, 2005; Nasif et al, 2005b). Thus, it may well be that more 'recreational' exposure to cocaine results in differential effects on PL excitability than is observed in paradigms associated with more compulsive behaviors.

This is, to our knowledge, the first report that cocaine exposure leads to a decrease in IL intrinsic excitability. Moreover, the divergent effects of cocaine selfadministration and extinction on PL and IL neuron excitability underscores proposed functional differences in these regions with regard to reward seeking or inhibition of responses (Gourley and Taylor, 2016; Moorman et al, 2014).
Comparisons of properties of PL and IL neurons under various treatment conditions indicated no baseline differences in resting membrane potential, but a significant difference in rheobase between PL and IL neurons in Saline-Vehicle and Cocaine- $4 \mathrm{mg} / \mathrm{kg}$ groups was observed, suggesting an intrinsic difference in excitability between these populations that is independent of resting potential (Table 1). Given that neurons from Saline-Vehicle and Cocaine-Vehicle groups did not differ in fAHP, this suggests that cocaine may decrease neuronal excitability by reducing $\mathrm{Na}+$ channel currents in IL neurons. Furthermore, riluzole restored the bidirectional changes in intrinsic excitability induced by cocaine experience. Interestingly, although riluzole reversed the cocaine-induced increase and decrease in excitability in the PL and IL, respectively, it had marginal effects on measures of excitability in saline-experienced rats. For example, there was no significant effect of riluzole on response to increasing current stimulation in either PL or IL neurons (Figures $2 \mathrm{c}$ and $3 \mathrm{~b}$ ). However, we did observe a significant decrease in ISI in the PL (Figure 2e) and in the max number of spikes recorded in neurons from salineexperienced rats in the IL (Figure 3c). These inconsistent effects in control rats may reflect the fact that riluzole was administered systemically $30 \mathrm{~min}$ before preparation of tissue for recording, and is a reversible inhibitor of $\mathrm{Na}+$ channels in vitro (Cao et al, 2002; Siniscalchi et al, 1997). These observations underscore the likelihood that the effect of riluzole on neuronal excitability in cocaine-extinguished rats is a reflection of amelioration of drug-induced adaptations.

Although we do not know the precise mechanism(s) responsible for the effects of riluzole on reinstatement, it is notable that in addition to acting as a $\mathrm{Na}+$ channel inhibitor, riluzole also modulates activation and inactivation of potassium channels, inhibits activation of voltage-gated $\mathrm{Ca}^{2+}$ channels and persistent sodium channels, increases AMPA receptor surface expression (GluA1 and GluA2) and AMPAinduced depolarization, increases BDNF, activates GABA receptor, and increases glutamate uptake by increasing GLT-1 transporter function and expression (Du et al, 2007; Pittenger et al, 2008). We believe that the pharmacological effects of riluzole in the PL and IL may rely on differentially weighted mechanisms of action. One mechanism by which riluzole may renormalize PL hyperexcitability is by modulating persistent sodium channels and $\mathrm{Ca}^{2+}$-dependent potassium channels. One mechanism by which riluzole may renormalize cocaineinduced IL hypoexcitability is by increasing the expression of BDNF and AMPA receptor subunits. Future electrophysiology experiments designed to assess pre- and postsynaptic components of synaptic transmission and plasticity, including paired-pulse ratio and AMPA/NMDA ratio, will be used to elucidate the precise way in which riluzole affects reinstatement behavior.

Furthermore, evidence indicates that BDNF can enhance intrinsic excitability (Guo et al, 2017), and in fact infusion of BDNF into the ventral hippocampus selectively increased the firing rate of IL, but not PL neurons, in fear conditioned rats (Rosas-Vidal et al, 2014). Interestingly, riluzole decreased the fAHP, suggesting that inhibition of $\mathrm{K}+$ channels contribute to normalized intrinsic excitability of IL neurons. Future studies will be important to assess how both fundamental cellular properties and their responsiveness to 
learning and to reward contribute to the complex functional outputs from these regions.

\section{Riluzole Restores NAc GLT-1 Expression in Cocaine- Extinguished Rats}

Numerous studies have demonstrated that riluzole not only modulates $\mathrm{Na}+$ and $\mathrm{K}+$ channels that are important in the neuronal excitability, but also increases glutamate uptake via GLT-1 expression and activity (Banasr et al, 2010; Brothers et al, 2013; Carbone et al, 2012; Frizzo et al, 2004; Fumagalli et al, 2008; Gourley et al, 2012; Liu et al, 2011). Furthermore, it has been thoroughly demonstrated that cocaine leads to decreased GLT-1 expression and activity in the NAc (Fischer et al, 2013; Fischer-Smith et al, 2012; Knackstedt et al, 2010; Reissner et al, 2014). The present study shows that the cocaine-induced reduction in NAc GLT-1 is reversed by riluzole, but that NAc GLT-1 expression is unaffected by riluzole treatment in saline-administering rats. Interestingly, it has also previously been shown that ceftriaxone, which increases NAc GLT-1 expression in cocaine-extinguished rats, does not affect GLT-1 expression in cocaine-naive rats (Knackstedt et al, 2010). Importantly, riluzole can also increase glutamate uptake by enhancing GLT-1 function without a change in expression (Carbone et al, 2012; Fumagalli et al, 2008).

In summary, riluzole can impair cocaine reinstatement and reverse several cocaine-induced adaptations within the reward circuitry, indicating promise for pharmacotherapeutic intervention for cocaine relapse. A single, small-scale human trial showed that riluzole lacked effect on cocaine use when taken during cocaine dependence (Ciraulo et al, 2005). Importantly, this was a small study in which medication compliance was not verified. Accordingly, given findings from preclinical literature, we propose that use of riluzole as pharmacological intervention, and particularly targeting multiple components of glutamatergic signaling, carries potential for intervention against cocaine relapse.

\section{FUNDING AND DISCLOSURE}

The authors declare no conflict of interest.

\section{ACKNOWLEDGMENTS}

This work was supported by R00DA031790 (to KJR), R01DA041455 (to KJR), and T32DA007244 (to KLH). We thank Mounira Banasr for consultation on riluzole preparation, and members of the Reissner lab for constructive criticisms on a previous version of this manuscript.

\section{REFERENCES}

Ahn HS, Kim SE, Jang HJ, Kim MJ, Rhie DJ, Yoon SH et al (2006). Interaction of riluzole with the closed inactivated state of $\mathrm{Kv} 4.3$ channels. J Pharmacol Exp Ther 319: 323-331.

Banasr M, Chowdhury GM, Terwilliger R, Newton SS, Duman RS, Behar KL et al (2010). Glial pathology in an animal model of depression: reversal of stress-induced cellular, metabolic and behavioral deficits by the glutamate-modulating drug riluzole. Mol Psychiatry 15: 501-511.
Bean BP (2007). The action potential in mammalian central neurons. Nat Rev Neurosci 8: 451-465.

Bowers MS, Chen BT, Bonci A (2010). AMPA receptor synaptic plasticity induced by psychostimulants: the past, present, and therapeutic future. Neuron 67: 11-24.

Brothers HM, Bardou I, Hopp SC, Kaercher RM, Corona AW, Fenn AM et al (2013). Riluzole partially rescues age-associated, but not LPS-induced, loss of glutamate transporters and spatial memory. J Neuroimmune Pharmacol 8: 1098-1105.

Buchta W, Riegel A (eds) (2015). Cocaine Self-Administration and Cue-Reinstatement Disrupt Kv7 (KCNQ) Channel Inhibition in the Prefrontal Cortex. Society for Neuroscience: Chicago, IL.

Cao YJ, Dreixler JC, Couey JJ, Houamed KM (2002). Modulation of recombinant and native neuronal SK channels by the neuroprotective drug riluzole. Eur J Pharmacol 449: 47-54.

Carbone M, Duty S, Rattray M (2012). Riluzole elevates GLT-1 activity and levels in striatal astrocytes. Neurochem Int 60: 31-38.

Cheah BC, Vucic S, Krishnan AV, Kiernan MC (2010). Riluzole, neuroprotection and amyotrophic lateral sclerosis. Curr Med Chem 17: 1942-1199.

Chen BT, Yau HJ, Hatch C, Kusumoto-Yoshida I, Cho SL, Hopf FW et al (2013). Rescuing cocaine-induced prefrontal cortex hypoactivity prevents compulsive cocaine seeking. Nature 496: 359-362.

Ciraulo DA, Sarid-Segal O, Knapp CM, Ciraulo AM, LoCastro J, Bloch DA et al (2005). Efficacy screening trials of paroxetine, pentoxifylline, riluzole, pramipexole and venlafaxine in cocaine dependence. Addiction 100((Suppl 1)): 12-22.

Danbolt NC (2001). Glutamate uptake. Prog Neurobiol 65: 1-105.

Dong Y, Nasif FJ, Tsui JJ, Ju WY, Cooper DC, Hu XT et al (2005). Cocaine-induced plasticity of intrinsic membrane properties in prefrontal cortex pyramidal neurons: adaptations in potassium currents. J Neurosci 25: 936-940.

Du J, Suzuki K, Wei Y, Wang Y, Blumenthal R, Chen Z et al (2007). The anticonvulsants lamotrigine, riluzole, and valproate differentially regulate AMPA receptor membrane localization: relationship to clinical effects in mood disorders. Neuropsychopharmacology 32: 793-802.

Duprat F, Lesage F, Patel AJ, Fink M, Romey G, Lazdunski M (2000). The neuroprotective agent riluzole activates the two $P$ domain $\mathrm{K}(+)$ channels TREK-1 and TRAAK. Mol Pharmacol 57: 906-912.

Duvarci S, Pare D (2007). Glucocorticoids enhance the excitability of principal basolateral amygdala neurons. I Neurosci 27: 4482-4491.

Faber ES, Sah P (2002). Physiological role of calcium-activated potassium currents in the rat lateral amygdala. J Neurosci 22: $1618-1628$.

Faber ES, Sah P (2003). Calcium-activated potassium channels: multiple contributions to neuronal function. Neuroscientist 9: 181-194.

Fischer KD, Houston AC, Rebec GV (2013). Role of the major glutamate transporter GLT1 in nucleus accumbens core versus shell in cue-induced cocaine-seeking behavior. J Neurosci 33: 9319-9327.

Fischer-Smith KD, Houston AC, Rebec GV (2012). Differential effects of cocaine access and withdrawal on glutamate type 1 transporter expression in rat nucleus accumbens core and shell. Neuroscience 210: 333-339.

Frizzo ME, Dall'Onder LP, Dalcin KB, Souza DO (2004). Riluzole enhances glutamate uptake in rat astrocyte cultures. Cell Mol Neurobiol 24: 123-128.

Fumagalli E, Funicello M, Rauen T, Gobbi M, Mennini T (2008). Riluzole enhances the activity of glutamate transporters GLAST, GLT1 and EAAC1. Eur J Pharmacol 578: 171-176.

Gipson CD, Kupchik YM, Shen HW, Reissner KJ, Thomas CA, Kalivas PW (2013). Relapse induced by cues predicting cocaine depends on rapid, transient synaptic potentiation. Neuron 77: $867-872$ 
Gourley SL, Espitia JW, Sanacora G, Taylor JR (2012). Antidepressant-like properties of oral riluzole and utility of incentive disengagement models of depression in mice. Psychopharmacology 219: 805-814.

Gourley SL, Taylor JR (2016). Going and stopping: dichotomies in behavioral control by the prefrontal cortex. Nat Neurosci 19: 656-664.

Guo JQ, Deng HH, Bo X, Yang XS (2017). Involvement of BDNF/ TrkB and ERK/CREB axes in nitroglycerin-induced rat migraine and effects of estrogen on these signals in the migraine. Biol Open 6: 8-16.

Hearing M, Kotecki L, Marron Fernandez de Velasco E, FajardoSerrano A, Chung HJ, Lujan R et al (2013). Repeated cocaine weakens $\mathrm{GABA}(\mathrm{B})$-Girk signaling in layer $5 / 6$ pyramidal neurons in the prelimbic cortex. Neuron 80: 159-170.

Javitt DC, Schoepp D, Kalivas PW, Volkow ND, Zarate C, Merchant $\mathrm{K}$ et al (2011). Translating glutamate: from pathophysiology to treatment. Sci Transl Med 3: 102mr102.

Kalivas PW, Volkow ND (2011). New medications for drug addiction hiding in glutamatergic neuroplasticity. Mol Psychiatry 16: 974-986.

Kamii H, Kurosawa R, Taoka N, Shinohara F, Minami M, Kaneda K (2015). Intrinsic membrane plasticity via increased persistent sodium conductance of cholinergic neurons in the rat laterodorsal tegmental nucleus contributes to cocaine-induced addictive behavior. Eur J Neurosci 41: 1126-1138.

Knackstedt LA, Melendez RI, Kalivas PW (2010). Ceftriaxone restores glutamate homeostasis and prevents relapse to cocaine seeking. Biol Psychiatry 67: 81-84.

Korpi ER, den Hollander B, Farooq U, Vashchinkina E, Rajkumar $\mathrm{R}$, Nutt DJ et al (2015). Mechanisms of action and persistent neuroplasticity by drugs of abuse. Pharmacol Rev 67: 872-1004.

Kourrich S, Calu DJ, Bonci A (2015). Intrinsic plasticity: an emerging player in addiction. Nat Rev Neurosci 16: 173-184.

LaLumiere RT, Niehoff KE, Kalivas PW (2010). The infralimbic cortex regulates the consolidation of extinction after cocaine selfadministration. Learn Mem 17: 168-175.

Lamanauskas N, Nistri A (2008). Riluzole blocks persistent $\mathrm{Na}+$ and $\mathrm{Ca} 2+$ currents and modulates release of glutamate via presynaptic NMDA receptors on neonatal rat hypoglossal motoneurons in vitro. Eur J Neurosci 27: 2501-2514.

Liu AY, Mathur R, Mei N, Langhammer CG, Babiarz B, Firestein BL (2011). Neuroprotective drug riluzole amplifies the heat shock factor 1 (HSF1)- and glutamate transporter 1 (GLT1)-dependent cytoprotective mechanisms for neuronal survival. J Biol Chem 286: $2785-2794$.

Lourenco Da Silva A, Hoffmann A, Dietrich MO, Dall'Igna OP, Souza DO, Lara DR (2003). Effect of riluzole on MK-801 and amphetamine-induced hyperlocomotion. Neuropsychobiology 48: 27-30.

Luscher C, Malenka RC (2011). Drug-evoked synaptic plasticity in addiction: from molecular changes to circuit remodeling. Neuron 69: 650-663.

Machado-Vieira R, Salvadore G, Ibrahim LA, Diaz-Granados N, Zarate CA Jr (2009). Targeting glutamatergic signaling for the development of novel therapeutics for mood disorders. Curr Pharm Des 15: 1595-1611.

McCullumsmith RE, Sanacora G (2015). Regulation of extrasynaptic glutamate levels as a pathophysiological mechanism in disorders of motivation and addiction. Neuropsychopharmacology 40: 254-255.

McFarland K, Kalivas PW (2001). The circuitry mediating cocaineinduced reinstatement of drug-seeking behavior. J Neurosci 21: 8655-8663.

McFarland K, Lapish CC, Kalivas PW (2003). Prefrontal glutamate release into the core of the nucleus accumbens mediates cocaineinduced reinstatement of drug-seeking behavior. J Neurosci 23: 3531-3537.
Meininger V, Lacomblez L, Salachas F (2000). What has changed with riluzole? J Neurol 247: 19-22.

Moorman DE, James MH, McGlinchey EM, Aston-Jones G (2014). Differential roles of medial prefrontal subregions in the regulation of drug seeking. Brain Res 1628(Pt A): 130-146.

Murphy-Royal C, Dupuis J, Groc L, Oliet SH (2017). Astroglial glutamate transporters in the brain: Regulating neurotransmitter homeostasis and synaptic transmission. J Neurosci Res 95: $2140-2151$.

Nasif FJ, Hu XT, White FJ (2005a). Repeated cocaine administration increases voltage-sensitive calcium currents in response to membrane depolarization in medial prefrontal cortex pyramidal neurons. J Neurosci 25: 3674-3679.

Nasif FJ, Sidiropoulou K, Hu XT, White FJ (2005b). Repeated cocaine administration increases membrane excitability of pyramidal neurons in the rat medial prefrontal cortex. $J$ Pharmacol Exp Ther 312: 1305-1313.

Oh MM, Oliveira FA, Disterhoft JF (2010). Learning and aging related changes in intrinsic neuronal excitability. Front Aging Neurosci 2: 2.

Otis JM, Mueller D (2017). Reversal of cocaine-associated synaptic plasticity in prefrontal cortex. Neuropsychopharmacology 42: 2000-2010.

Pittenger C, Coric V, Banasr M, Bloch M, Krystal JH, Sanacora G (2008). Riluzole in the treatment of mood and anxiety disorders. CNS Drugs 22: 761-786.

Porter JT, Johnson CK, Agmon A (2001). Diverse types of interneurons generate thalamus-evoked feedforward inhibition in the mouse barrel cortex. J Neurosci 21: 2699-2710.

Reissner KJ, Brown RM, Spencer S, Tran PK, Thomas CA, Kalivas PW (2014). Chronic administration of the methylxanthine propentofylline impairs reinstatement to cocaine by a GLT-1-dependent mechanism. Neuropsychopharmacology 39: 499-506.

Reissner KJ, Gipson CD, Tran PK, Knackstedt LA, Scofield MD, Kalivas PW (2015). Glutamate transporter GLT-1 mediates $\mathrm{N}$-acetylcysteine inhibition of cocaine reinstatement. Addict Biol 20: $316-323$.

Roberts-Wolfe DJ, Kalivas PW (2015). Glutamate transporter GLT-1 as a therapeutic target for substance use disorders. CNS Neurol Disord Drug Targets 14: 745-756.

Robinson MB, Jackson JG (2016). Astroglial glutamate transporters coordinate excitatory signaling and brain energetics. Neurochem Int 98: 56-71.

Rosas-Vidal LE, Do-Monte FH, Sotres-Bayon F, Quirk GJ (2014). Hippocampal-prefrontal BDNF and memory for fear extinction. Neuropsychopharmacology 39: 2161-2169.

Santini E, Quirk GJ, Porter JT (2008). Fear conditioning and extinction differentially modify the intrinsic excitability of infralimbic neurons. I Neurosci 28: 4028-4036.

Sari Y, Smith KD, Ali PK, Rebec GV (2009). Upregulation of GLT1 attenuates cue-induced reinstatement of cocaine-seeking behavior in rats. J Neurosci 29: 9239-9243.

Scofield MD, Li H, Siemsen BM, Healey KL, Tran PK, Woronoff N et al (2016). Cocaine self-administration and extinction leads to reduced glial fibrillary acidic protein expression and morphometric features of astrocytes in the nucleus accumbens core. Biol Psychiatry 80: 207-215.

Sepulveda-Orengo MT, Lopez AV, Soler-Cedeno O, Porter JT (2013). Fear extinction induces mGluR5-mediated synaptic and intrinsic plasticity in infralimbic neurons. J Neurosci 33: 7184-7193.

Siniscalchi A, Bonci A, Mercuri NB, Bernardi G (1997). Effects of riluzole on rat cortical neurones: an in vitro electrophysiological study. Br J Pharmacol 120: 225-230.

Spencer S, Kalivas PW (2017). Glutamate transport: a new bench to bedside mechanism for treating drug abuse. Int J Neuropsychopharmacol 20: 797-812. 
Sugiyama A, Saitoh A, Iwai T, Takahashi K, Yamada M, SasakiHamada $S$ et al (2012). Riluzole produces distinct anxiolytic-like effects in rats without the adverse effects associated with benzodiazepines. Neuropharmacology 62: 2489-2498.

Ting JT, Daigle TL, Chen Q, Feng G (2014). Acute brain slice methods for adult and aging animals: application of targeted patch clamp analysis and optogenetics. Methods Mol Biol 1183: 221-242.

Traynor BJ, Bruijn L, Conwit R, Beal F, O'Neill G, Fagan SC et al (2006). Neuroprotective agents for clinical trials in ALS: a systematic assessment. Neurology 67: 20-27.
Tzingounis AV, Wadiche JI (2007). Glutamate transporters: confining runaway excitation by shaping synaptic transmission. Nat Rev Neurosci 8: 935-947.

Uys JD, Reissner KJ (2011). Glutamatergic neuroplasticity in cocaine addiction. Prog Mol Biol Transl Sci 98: 367-400.

Wolf ME (2016). Synaptic mechanisms underlying persistent cocaine craving. Nat Rev Neurosci 17: 351-365.

Xu L, Enyeart JA, Enyeart JJ (2001). Neuroprotective agent riluzole dramatically slows inactivation of Kv1.4 potassium channels by a voltage-dependent oxidative mechanism. J Pharmacol Exp Ther 299: 227-237. 